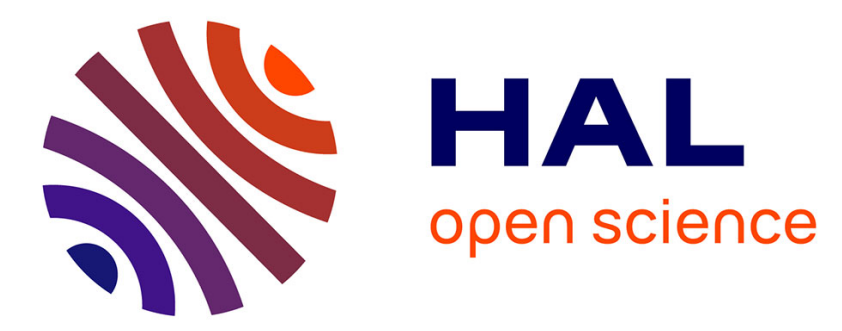

\title{
Ligand-Controlled Regiodivergent Hydroformylation of Ynamides: A Stereospecific and Regioselective Access to 2- and 3-Aminoacroleins
}

Patrick Wagner, Morgan Donnard, Nicolas Girard

\section{- To cite this version:}

Patrick Wagner, Morgan Donnard, Nicolas Girard. Ligand-Controlled Regiodivergent Hydroformylation of Ynamides: A Stereospecific and Regioselective Access to 2- and 3-Aminoacroleins. Organic Letters, 2019, 10.1021/acs.orglett.9b03566 . hal-02322712

\section{HAL Id: hal-02322712 \\ https://hal.science/hal-02322712}

Submitted on 5 Nov 2020

HAL is a multi-disciplinary open access archive for the deposit and dissemination of scientific research documents, whether they are published or not. The documents may come from teaching and research institutions in France or abroad, or from public or private research centers.
L'archive ouverte pluridisciplinaire HAL, est destinée au dépôt et à la diffusion de documents scientifiques de niveau recherche, publiés ou non, émanant des établissements d'enseignement et de recherche français ou étrangers, des laboratoires publics ou privés. 


\title{
Ligand-Controlled Regiodivergent Hydroformylation of Ynamides: A Stereospecific and Regioselective Access to 2- and 3-Aminoacroleins.
}

\author{
Patrick Wagner, ${ }^{\dagger}$ Morgan Donnard, ${ }^{\ddagger *}$ Nicolas Girard ${ }^{\dagger *}$ \\ † Université de Strasbourg, CNRS (LIT UMR 7200); Faculté de Pharmacie; F-67000 Strasbourg \\ *Université de Strasbourg, CNRS, Université de Haute-Alsace (LIMA UMR 7042); École Européenne de Chimie, Poly- \\ mères et Matériaux (ECPM); F-67000 Strasbourg
}

Keywords: Hydroformylation, regiodivergent, ynamide, enamine, enaminal.

\begin{abstract}
The rhodium-catalyzed hydroformylation of ynamides is described and give selectively access to 2- or 3-aminoacrolein derivatives. The regioselectivity of this carbonylation can be completely controlled at will thanks to the nature of the ligand used. This represent the first example of regiodivergent alkyne hydroformylation. The influence of the substituents on the different positions of the ynamide has been investigated and it appeared that this reaction is tolerant to a wide range of functional groups.

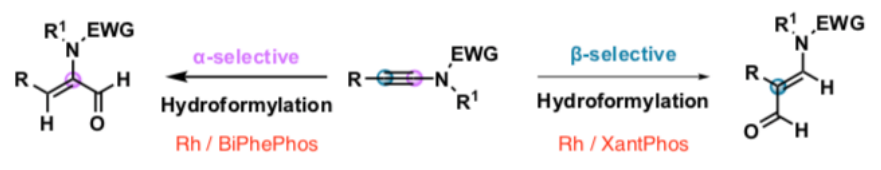

80 years after having been discovered by Otto Roelen, ${ }^{1}$ hydroformylation reaction has demonstrated over the decades its strong synthetic power and became the most important homogenous catalytic process in the industry. ${ }^{2,3}$ This reaction is highly atom economic, as it functionalizes a carbon-carbon multiple bond with an aldehyde generated from readily available gases (i.e. $\mathrm{CO}$ and $\mathrm{H}_{2}$ ) and its relatively mild reaction conditions have allowed it to be used as the key transformation in elegant tandem/domino processes. ${ }^{4}$ Since its first report by Wender in $1957,{ }^{5}$ alkyne hydroformylation has been much less investigated than that of alkenes. ${ }^{6}$ In recent years, major progresses have been performed in alkyne hydroformylation. One of the most notable being Buchwald's introduction of BiPhePhos as ligand in rhodium-catalyzed hydrocarbonylation ${ }^{7}$ allowing to significantly decrease the overreduction of the newly formed $\alpha, \beta$-unsaturated aldehyde. Since then, significant efforts have been done by several groups such as Alper, ${ }^{8}$ Hidai, ${ }^{9}$ le Floch and Sanchez, ${ }^{10}$ Breit, ${ }^{11}$ Beller ${ }^{12}$ or Dong and Zhang ${ }^{13}$ in order to increase the regio/stereoselectivity and to suppress as much as possible the byproducts coming from undesired hydrogenation processes. In addition, very recently, You ${ }^{14}$ introduced the first syngas-free alkyne hydroformylation. However, if the overreduction can be now considered as controlled, in the case of internal dissymmetric alkynes a lot of work remains to be done in terms of regiocontrol of the reaction. To date, three possibilities of control have been investigated (Figure 1). The first relies on the classical steric control. In that case the metal center will be introduced on the less hindered side of the alkyne. The second is based on the use of phenylacetylene derivatives. In that specific case the reaction mainly drives to the introduction of the formyl group on the same carbon as the aromatic moiety.

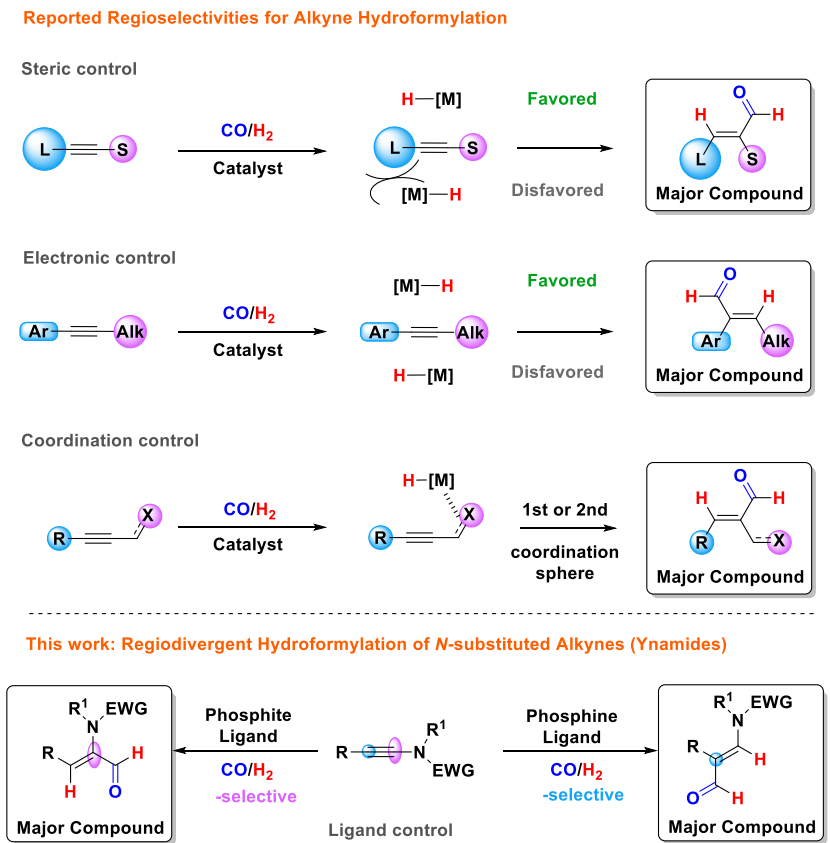

Figure 1. Comparison between reported alkyne-hydroformylation regioselectivity and this work reporting the ligand-controlled regiodivergent hydroformylation of ynamides.

The third option is the use of a directing group that can chelate the metal center of the catalytic species. And finally, the last one has been recently reported by Breit and coworkers. ${ }^{15}$ They demonstrated that a rhodium-catalyzed tandem regioselective hydroformylation/ hydrogenation of internal alkynes can be performed thanks to the use of a guanidine based ligand that allows supramolecular interactions between the organometallic 
complex and the substrate. If all these approaches can lead from good to very good regioselectivity, notably, in all cases, its controlled inversion was never reported.

In this context, we have decided to focus our attention on the use of particular alkynes directly linked to a nitrogen atom, namely the ynamides. ${ }^{16}$ These compounds have emerged over the last 15 years as remarkable building blocks. Notably, they are precious precursors of poly-substituted enamines that can be subsequently involved in the synthesis of valuable complex molecules. In our opinion, this family of molecules could be quite interesting as hydroformylation substrates for several reasons. First, the use of these species in hydroformylation could lead to efficient and general access to poly-functionalized aminoacrolein derivatives that are building blocks with high synthetic potential but fairly difficult to synthesize. ${ }^{17}$ Secondly, ynamides are particular unsymmetrical alkynes. On the one hand, due to the presence of the nitrogen atom linked to the carbon-carbon triple bond, this unsaturation is remarkably electron-rich. This activation could result in a high tendency to be directly hydrogenated to form the corresponding enamine 4 but its strong polarization could also help to control the regioselectivity of the hydroformylation reaction. On the other hand the electron-withdrawing group attached to the nitrogen can act as a directing group and could also favor one regioisomer over the other. ${ }^{18}$ All together these parameters represent as many challenges but, being tamed, they can be regarded as an asset to regioselectively perform the hydroformylation to obtain at will an isomer or the other (2 or $\mathbf{3}) .{ }^{19}$ In this paper, we demonstrate that ynamides undergo efficient regiodivergent ligand-controlled hydroformylations with good to very good selectivity. To the best of our knowledge this is the first example of a regiodivergent hydroformylation of alkynes (figure 1).

To begin our investigations, a simple ynamide 1a bearing an alkyl chain on both the nitrogen and the alkyne and a tosyl group as electron withdrawing group has been chosen as substrate and the most efficient conditions reported in the literature for the hydroformylation of alkyne were first tested (i.e. triphenyl phosphine as ligand, toluene as solvent at $70{ }^{\circ} \mathrm{C}$ under 5 bar of syngas overnight) (table 1.1 entry 1 ). The reaction took place with a very low conversion. The main product formed was the reduced compound $4 \mathbf{a}$ (68\% of the converted material) but traces of the targeted aldehydes have been detected and the NMR analyses showed that the $\beta$ isomer 3a was clearly favored (ratio $\mathbf{2 a} / \mathbf{3} \mathbf{a}=25 / 75$ ). To improve this first encouraging result, we have then decided to test different ligands to evaluate their effect on the overall reaction results. Remarkably when the ligand was changed to $\mathrm{P}(\mathrm{OPh})_{3}$ the conversion increased but more interestingly the ratio $\mathbf{2 a} / \mathbf{3} \mathbf{a}$ was completely inverted (table 1.1 entry 2). Both together these two results were validating our idea that the regioselectivity of the hydroformylation of ynamides could be controlled in one direction or the other. After the test of several bidentate ligands (Xantphos ${ }^{20},(R)$-DMSEGPHOS $^{21}$, BiPhePhos ${ }^{22}$, TriBiPhos ${ }^{23}$, for structures see table 1), only Xantphos and BiPhePhos (BPP) confirmed this differential selectivity between phosphine and phosphite ligands while increasing the conversion to a synthetically useful level (table 1.1 entries 3-6). However, if the reaction conditions seemed to be optimal when using Xantphos as ligand (high regioselectivity and only traces of direc t hydrogenation), a significant amount of the reduced compound 4a was remaining when using BiPhePhos. Notably, the isomerization of the newly formed C-C double bond has never been observed as only the $Z$ isomer was systematically obtained.
Table 1. Optimization of the reaction conditions

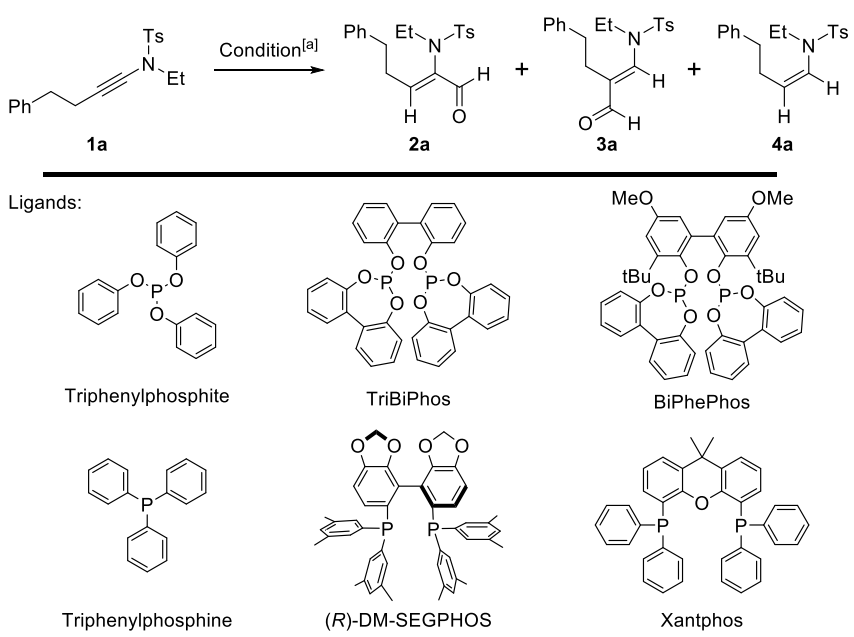

Table 1.1 Ligand and solvent optimization ${ }^{[\mathrm{a}]}$

\begin{tabular}{|c|c|c|c|c|c|}
\hline Entry & Ligand & Solvent & $2 \mathbf{a} / 3 \mathbf{a}$ & $(2 a+3 a) / 4 a$ & Yield Ald. $(\%)^{|c|}$ \\
\hline 1 & $\mathrm{P}(\mathrm{Ph})_{3}$ & Toluene & $25 / 75$ & $32 / 68$ & n.d. ${ }^{[\mathrm{b}]}$ \\
\hline 2 & $\mathrm{P}(\mathrm{OPh})_{3}$ & Toluene & $71 / 29$ & $54 / 46$ & 38 \\
\hline 3 & Xantphos & Toluene & $5 / 95$ & $92 / 8$ & 75 \\
\hline 4 & $\begin{array}{l}(R) \text {-DM- } \\
\text { SEGPHOS }\end{array}$ & Toluene & n.d. & n.d. & n.d. ${ }^{[\mathrm{d}]}$ \\
\hline 5 & BiPhePhos & Toluene & $81 / 19$ & $63 / 37$ & $\mathbf{5 7}$ \\
\hline 6 & TriBiPhos & Toluene & n.d. & n.d. & n.d. ${ }^{[\mathrm{d}]}$ \\
\hline 7 & BiPhePhos & Hexane & $76 / 24$ & $60 / 40$ & 56 \\
\hline 8 & BiPhePhos & DCE & $76 / 24$ & $67 / 33$ & 59 \\
\hline 9 & BiPhePhos & $\mathrm{CH}_{3} \mathrm{CN}$ & $82 / 18$ & $61 / 39$ & 42 \\
\hline
\end{tabular}

[a] $\mathrm{Rh}(\mathrm{CO})_{2}$ (acac) $(2 \mathrm{~mol} \%)$, ligand ( $\left.6 \mathrm{~mol} \%\right), 1 \mathrm{a}$ (1 equiv., 0.03 mol. $\left.\mathrm{L}^{-1}\right), \mathrm{CO} / \mathrm{H}_{2}\left(1: 1,5\right.$ bar), $70^{\circ} \mathrm{C}, 16 \mathrm{~h}$; Ratios determined by ${ }^{1} \mathrm{H}$ NMR analysis of the crude. [b] conversion $=15 \%$. [c] isolated yield of $\mathbf{2 a}+\mathbf{3 a}$. [d] conversion $<5 \%$. n. d. $=$ not determined.

Table 1.2. Optimization of $\mathrm{CO} / \mathrm{H}_{2}$ ratio and pressure when BiPhePhos used as ligand ${ }^{[a]}$

\begin{tabular}{|c|c|c|c|c|c|}
\hline Entry & $\mathrm{CO} / \mathrm{H}_{2}$ & Pressure & $2 a / 3 a$ & $(2 a+3 a) / 4 a$ & Yield Ald. $(\%)^{[b]}$ \\
\hline 1 & $1: 1$ & 5 bar & $81 / 19$ & $63 / 37$ & 57 \\
\hline 2 & $1: 1$ & $10 \mathrm{bar}$ & $75 / 25$ & $70 / 30$ & 60 \\
\hline 3 & $1: 1$ & $2.5 \mathrm{bar}$ & $79 / 21$ & $65 / 35$ & 55 \\
\hline 4 & $3: 1$ & 10 bar & $71 / 29$ & $82 / 18$ & 77 \\
\hline 5 & $5: 1$ & 10 bar & $70 / 30$ & $84 / 16$ & 75 \\
\hline
\end{tabular}

[a] $\mathrm{Rh}(\mathrm{CO})_{2}$ (acac) $(2 \mathrm{~mol} \%)$, BiPhePhos $(6 \mathrm{~mol} \%)$, $1 \mathrm{a}(1$ equiv., 0.03 mol. $\mathrm{L}^{-1}$ ), toluene, $70{ }^{\circ} \mathrm{C}, \mathrm{CO} / \mathrm{H}_{2}$ (see table), $16 \mathrm{~h}$. Ratios determined by ${ }^{1} \mathrm{H}$ NMR analysis of the crude; [b] isolated yield of $\mathbf{2 a}+\mathbf{3} \mathbf{a}$.

To optimize the reaction conditions when BiPhePhos is used as ligand, we have investigated diverse additional parameters. First, to evaluate the effect of the solvent on the chelation of the directing group, we performed a quick screening (hexane, DCE, acetonitrile). Notably, the regioselectivity remained relatively unaffected by the nature of it (table 1.1 entries 5, $6 \&$ 7). Then, pushing further our effort to reduce the fraction of the hydrogenated product $\mathbf{4 a}$, we have focused our attention on the gaseous part of the reaction. First, we demonstrated that the pressure of syngas $\left(\mathrm{CO} / \mathrm{H}_{2} 1: 1\right)$ was not significantly influencing the efficiency and the selectivity of the reaction (table 1.2 entries 1,2 
$\& 3)$. Then we investigated the effect of the proportion of carbon monoxide. For practical reasons, we performed this study at 10 bars. Remarkably an enrichment in $\mathrm{CO}$ of the gas mixture resulted in a significant decrease of the quantity of $\mathbf{4 a}$ formed without affecting the regioselectivity of the reaction (table 1.2 entries $4 \& 5$ ). The aldehydes could be obtained in more than $75 \%$ yield. Notably, performing the reaction at $40{ }^{\circ} \mathrm{C}$ resulted in a very low conversion of the starting material after $16 \mathrm{~h}$ (less than $3 \%$ ) while the reaction done at $100{ }^{\circ} \mathrm{C}$ gave the same results like the one at $70{ }^{\circ} \mathrm{C}$. In addition, we determined that $16 \mathrm{~h}$ were required for complete conversion in both cases.

With these two optimized reaction conditions in hands (Xantphos and BiPhePhos), the scope of the reaction has been investigated by performing both regiodivergent hydroformylations of diversely substituted ynamides (table 2).

First the influence of the substitution at the beta position of the ynamides has been evaluated. The functionalization of the alkyl chain with a protected alcohol for instance as in ynamide $\mathbf{1 b}$ did not affect the selectivity of the reaction (entry 3 and 4) but induced a slight decrease of the yield around $10 \%$. This could be potentially explained by the higher steric hindrance of the OTBS group in comparison to the previous phenyl ring. An aromatic ring such as a phenyl induced a remarkable increase of the direct reduction of $1 \mathbf{c}$ to the corresponding enamine $4 \mathbf{c}$ when BiPhePhos was used as ligand, however the regioselectivity was improved with an $8 / 2$ ratio in favor of $2 \mathbf{c}$ (entry 5). Interestingly, apart from a slight increase of the proportion of reduced side product $\mathbf{4 c}$, the hydroformylation of $\mathbf{1 c}$ using Xantphos as ligand gave similar results as 1a in terms of yield and regioselectivity. A silylated substituent such as TMS on the ynamides 1d led to complete inhibition of the reaction in both cases (entries $7 \& 8$ ) as only starting material was recovered after $16 \mathrm{~h}$. To explain this phenomenon, if the steric hindrance can be incriminated when Xantphos is used as ligand, the additional electronic effect induced by the silicon atom on the polarization of the $\mathrm{C}-\mathrm{C}$ triple bond as to be considered when BiPhePhos is employed (electronic impoverishment at the alpha position of the ynamide 1d).

The use of terminal ynamide 1e with BiPhePhos as ligand led to a significant increase in the reduced product $4 \mathrm{e}$. The low $26 \%$ yield observed and the apparent inversion of selectivity is most probably due to the degradation of the unstable enaminal $2 \mathrm{e}$ (entry 9). In a second time, the influence of the protecting group on the nitrogen has been evaluated. In our opinion, this point was crucial as the selectivity of our catalytic systems is based on the directing abilities of this moiety. Substrates bearing a carbamate group such as Boc (1) $)$, Moc (1g) or an oxazolidone (1h \& 1i) gave relatively similar results as the tosylated ynamide $1 \mathrm{a}$ both in terms of selectivity and yield (entries 11-18). Then the effect of the last point of diversity, i.e. the second substituent on the nitrogen atom, has been investigated. A benzyl group did not affect significantly the reactivity of the reaction as $\mathbf{1} \mathbf{j}$ gave similar results as 1a with both ligands (entry $19 \& 20$ ). An anilinebased ynamide $1 \mathbf{k}$ gave better results with both ligands in term of selectivity while the amount of the undesired reduction was significantly reduced (entries $21 \& 22$ ). A bulky substituent such as a tert-butyl group on the nitrogen of the ynamide 11 led to complete inhibition of the reaction with both ligands (entries $23 \& 24)$. Together with the observation made with the TMS group on the terminal position of $\mathbf{1 d}$ seems to demonstrate that the steric hindrance around the alkyne has dramatic effect on the conversion of the reaction as, in both cases (1d \& 11), the starting material was fully recovered after $16 \mathrm{~h}$.

The presence of an additional chelating moiety on the nitrogen side such as morpholine (1m) induced a slight decrease of the selectivity when BiPhePhos was used as ligand but notably the amount of reduced compound $\mathbf{4 m}$ was significantly increased (entry 25). However, when the reaction was performed with Xantphos, the reaction proceed with results in the classical range of the previous substrates (entry 26).

Interestingly, the use of an amino acid derivative bearing a carboxyl group as a chelating group (1n) induced in equivalent proportion an increase of the regioselectivity ( 2 vs 3) with BiPhePhos (entry 27) and a decrease of it with Xantphos (entry 28). Remarkably, the latter was accompanied with an increase of the undesired reduction leading to $4 \mathbf{n}$.

Finally, the steric parameter in the $\beta$ position was investigated using the relatively low bulky oxazolidinone as nitrogen moiety. Logically, with BiPhePhos as the ligand, the major isomer is systematically the $\alpha$ one, with good to very good selectivity. The steric control of the regioselectivity with Xantphos as ligand has been demonstrated. Indeed, the more the steric congestion increases, the more the proportion of $\alpha$ isomer significantly increases ultimately going to a total inversion of the selectivity in the case of a tert-butyl group.

Table 2. Scope and limitation of the reaction[a]
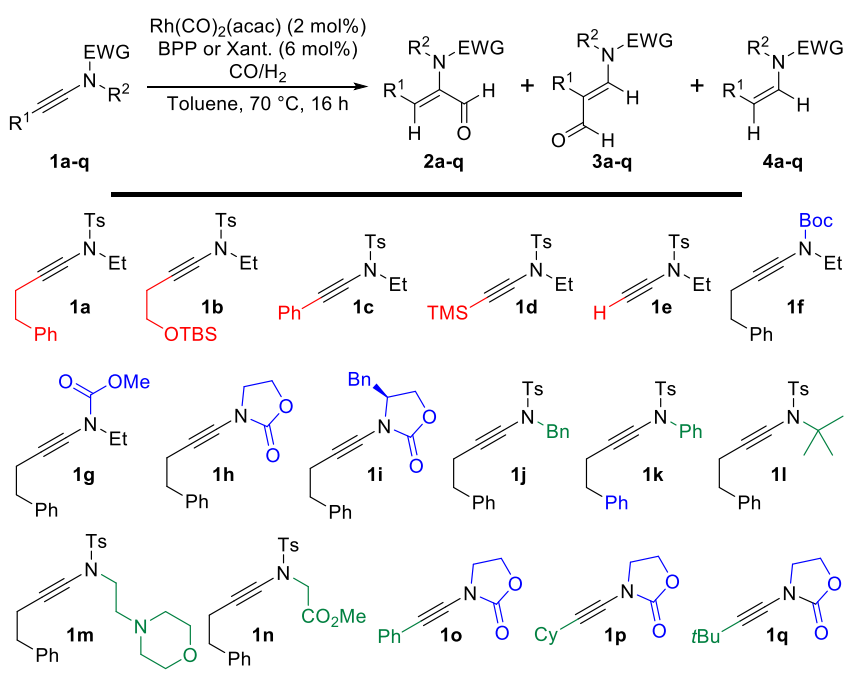

\begin{tabular}{cccccc|} 
Entry & Substrat & Ligand & $\mathbf{2 / 3}$ & $\begin{array}{c}\text { Ald./Red. } \\
\mathbf{( 2 + 3 ) / 4}\end{array}$ & ${\text { Yield Ald. }(\mathbf{\%})^{[\mathbf{b}]}}$ \\
\hline 1 & $\mathbf{1 a}$ & BiPhePhos & $70 / 30$ & $84 / 16$ & 75 \\
2 & $\mathbf{1 a}$ & Xantphos & $5 / 95$ & $92 / 8$ & 75 \\
3 & $\mathbf{1 b}$ & BiPhePhos & $68 / 32$ & $86 / 14$ & 67 \\
4 & $\mathbf{1 b}$ & Xantphos & $13 / 87$ & $91 / 9$ & 62 \\
5 & $\mathbf{1 c}$ & BiPhePhos & $80 / 20$ & $62 / 38$ & 54 \\
6 & $\mathbf{1 c}$ & Xantphos & $7 / 93$ & $86 / 14$ & 84 \\
7 & $\mathbf{1 d}$ & BiPhePhos & - & - & n.r. \\
8 & $\mathbf{1 d}$ & Xantphos & - & - & n.r. \\
9 & $\mathbf{1 e}$ & BiPhePhos & $22 / 78$ & $45 / 55$ & $26^{[\mathrm{cc}]}$ \\
10 & $\mathbf{1 e}$ & Xantphos & $5 / 95$ & $93 / 7$ & $54^{[\mathrm{cc}]}$ \\
11 & $\mathbf{1 f}$ & BiPhePhos & $78 / 22$ & $89 / 11$ & 66 \\
12 & $\mathbf{1 f}$ & Xantphos & $7 / 93$ & $>95 /<5$ & 68
\end{tabular}




$\begin{array}{lccccc}13 & \mathbf{1 g} & \text { BiPhePhos } & 73 / 27 & 87 / 13 & 62 \\ 14 & \mathbf{1 g} & \text { Xantphos } & 11 / 89 & >95 /<5 & 87 \\ 15 & \mathbf{1 h} & \text { BiPhePhos } & 70 / 30 & 85 / 15 & 68 \\ 16 & \mathbf{1 h} & \text { Xantphos } & 13 / 87 & >95 /<5 & 75 \\ 17 & \mathbf{1 i} & \text { BiPhePhos } & 57 / 43 & 88 / 12 & 77 \\ 18 & \mathbf{1 i} & \text { Xantphos } & 5 / 95 & >95 /<5 & 78 \\ 19 & \mathbf{1 j} & \text { BiPhePhos } & 60 / 40 & 86 / 14 & 78 \\ 20 & \mathbf{1 j} & \text { Xantphos } & 7 / 93 & 94 / 6 & 79 \\ 21 & \mathbf{1 k} & \text { BiPhePhos } & 81 / 19 & 93 / 7 & 66 \\ 22 & \mathbf{1 k} & \text { Xantphos } & <5 />95 & >95 /<5 & 72 \\ 23 & \mathbf{1 l} & \text { BiPhePhos } & - & - & n . r . \\ 24 & \mathbf{1 1} & \text { Xantphos } & - & - & \text { n.r. } \\ 25 & \mathbf{1 m} & \text { BiPhePhos } & 63 / 37 & 67 / 33 & 50 \\ 26 & \mathbf{1 m} & \text { Xantphos } & 6 / 94 & 92 / 8 & 73 \\ 27 & \mathbf{1 n} & \text { BiPhePhos } & 73 / 27 & 82 / 18 & 69 \\ 28 & \mathbf{1 n} & \text { Xantphos } & 25 / 75 & 79 / 21 & 74 \\ 29 & \mathbf{1 0} & \text { BiPhePhos } & 57 / 43 & 43 / 57 & 43 \\ 30 & \mathbf{1 0} & \text { Xantphos } & 25 / 75 & 74 / 26 & 54 \\ 31 & \mathbf{1 p} & \text { BiPhePhos } & 75 / 25 & 80 / 20 & 62 \\ 32 & \mathbf{1 p} & \text { Xantphos } & 62 / 38 & 91 / 9 & 79 \\ 33 & \mathbf{1 q} & \text { BiPhePhos } & >95 /<5 & 72 / 28 & 47^{\text {dd }} \\ & & & & & \end{array}$

$34 \quad 1 q \quad$ Xantphos $\quad>95 /<5 \quad 89 / 11 \quad 61^{[\mathrm{d}]}$

[a] $\mathrm{Rh}(\mathrm{CO})_{2}$ (acac) $(2 \% \mathrm{~mol})$, ligand $(6 \% \mathrm{~mol}), \mathbf{1 a}$ (1 equiv., 0.03 mol.L $\left.\mathrm{L}^{-1}\right), \mathrm{CO} / \mathrm{H}_{2}(1: 1,5$ bar with Xantphos and 1:5, 10 bar with BiPhePhos), toluene, $70{ }^{\circ} \mathrm{C}, 16 \mathrm{~h}$. Ratios determined by ${ }^{1} \mathrm{H}$ NMR analysis of the crude; [b] isolated yield of $\mathbf{2}+\mathbf{3}$. [c] only $\mathbf{3 e}$ has been isolated. $[\mathrm{d}]$ conversion $=70 \%$.

A possible explanation for the regioselectivity observed is based on the electronic richness of the phosphorus atom of the two families of ligands (figure 2). In our opinion the discriminating step is the hydrometallation one. In the case of phosphine ligands, the phosphorus is relatively electron-rich with a high sigma donating character ${ }^{24}$ resulting in a coordination to the rhodium strong enough to avoid the competitive coordination of the sulfonamide moiety of the ynamide. In that case, only the polarization and the steric hindrance of the alkyne is influencing the selectivity (Int. IIc) by installing the rhodium at the most electron rich and the less hindered position, namely the $\beta$ one (Int. IId). Under these conditions, the 3 -aminoacrolein 3a is the major product of the reaction (figure 2, path II).

Conversely, when the less sigma-donating phosphite ligand is used, ${ }^{10}$ the electron withdrawing group can coordinate the rhodium center (Int. Ic) to install the catalyst at the $\alpha$ position through a 5-exo-dig type hydrometallation (Int. Id) resulting in the formation of enaminal 2a as major product (figure 2, path I).

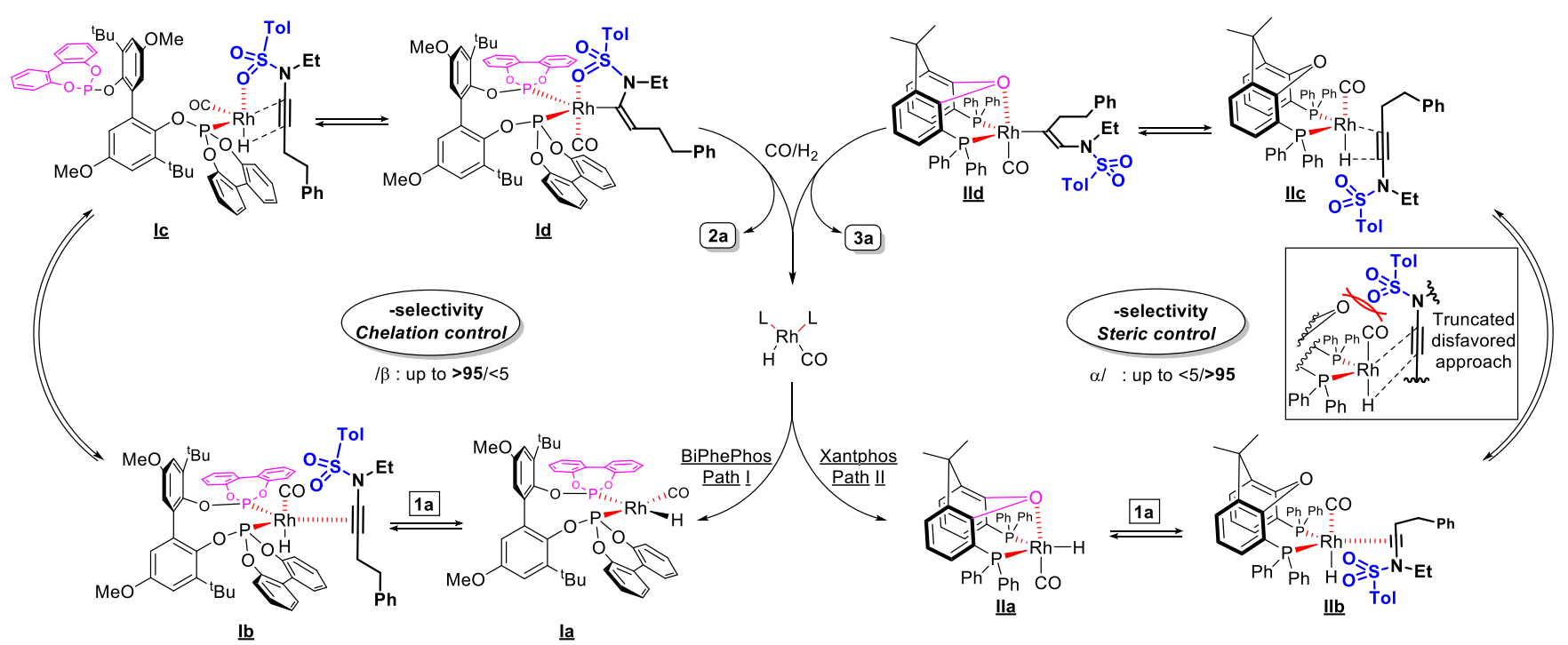

Figure 2. Hypothesis about the control of regioselectivity depending on the type of ligand used

To conclude, we have developed a regiodivergent access to 2and 3-amino acrolein derivatives based on the hydroformylation of ynamides. The stereospecificity is totally conserved as the reaction is always leading to the product resulting from the syn addition of the hydrogen and the formyl group on the alkyne moiety. The regioselectivity can be controlled by the ligand and can be inverted according to its nature. The use of BiPhePhos mainly furnishes the $\alpha$ one isomer while the use of Xantphos allows obtaining quasi-exclusively the $\beta$ one. More broadly, this study opens the door to regiodivergent hydroformylations of alkynes. The concept used, i.e. chelation versus steric control, to access selectively one or the other regioisomer could be generalized and is under investigation in our lab. In addition, further investigation both experimental and in-silico are under progress to better rationalize the regioselectivity of the reaction.

\section{ASSOCIATED CONTENT}

\section{Supporting Information}

Experimental procedures; full spectroscopic data for all new compounds; copies of ${ }^{1} \mathrm{H}$ and ${ }^{13} \mathrm{C}$ NMR spectra (PDF)

\section{AUTHOR INFORMATION}

\section{Corresponding Author}

* E-mail: donnard@unistra.fr

* E-mail: nicolas.girard@unistra.fr 


\section{ORCID}

Patrick Wagner: 0000-0002-8273-8329

* Morgan Donnard: 0000-0002-9303-4634

* Nicolas Girard: 0000-0003-4610-9872

\section{Notes}

The authors declare no competing financial interest.

\section{ACKNOWLEDGMENT}

The authors are grateful to the Centre National de la Recherche Scientifique (CNRS) and the Université de Strasbourg for financial support. Paul Chatelain, Maryame Sy and Pierre Hansjacob (University of Strasbourg) are acknowledged for preliminary investigations and substrate synthesis.

\section{REFERENCES}

(1) Roelen, O. DE 849548, 1944; US 1217066 [Chem. Abstr.1944, 38, 550].

(2) For relevant books on hydroformylation reactions, see: (a) Hydroformylation. Fundamentals, Processes and Application in Organic Synthesis (Eds: A. Börner, R. Franke), Wiley-VCH, Weinheim, 2016; (b) Hydroformylation for Organic Synthesis (Eds: M. Taddei, A. Mann), Topics in Current Organic Chemistry vol 342, Springer-Verlag, Berlin, 2013.

(3) For a recent review on applied hydroformylations, see: (a) Franke, R.; Selent, D.; Börner, A. Applied Hydroformylation. Chem. Rev. 2012, 112, 5675-5732; (b) Wiese, K.-D. ; Obst, D. in Catalytic Carbonylation Reactions (Ed.: M. Beller), Springer-Verlag, Berlin, 2010, pp. 1 - 33; (c) Casey, C. P.; Hartwig J. in Organotransition Metal Chemistry: From Bonding to Catalysis, Palgrave Macmillan, 2009, pp. 751 - 769; (d) Breit, B. in Metal Catalyzed Reductive C-C Bond Formation (Ed.: M. Krische), Springer, Berlin, 2007, p. 139.

(4) For selected recent examples see: (a) Spangenberg, T.; Airiau, E.; Bui The Thuong, M.; Donnard, M.; Billet, M.; Mann, A. Expeditious Syntheses of $( \pm)$-allo-Sedamine and $( \pm)$-allo-Lobeline via a Combination of Aza-Sakurai-Hosomi and Hydroformylation Reactions. Synlett 2008, 2859-2863; (b) Zill, N.; Schoenfelder, A.; Girard, N.; Taddei, M.; Mann, A. Stereoselective Multicomponent Assembly of Enantiopure Oxazolopiperidines and -azepines. J. Org. Chem., 2012, 77, 2246-2253; (c) Fang, X.; Jackstell, R.; Franke, R.; Beller, M. Domino-Hydroformylation/Aldol Condensation Catalysis: Highly Selective Synthesis of $\alpha, \beta$-Unsaturated Aldehydes from Olefins. Chem. Eur. J., 2014, 20, 13210-13216; (d) Regenass, P.; Margathe, J.-F.; Mann, A.; Suffert, J.; Hibert, M.; Girard, N.; Bonnet, D. Diastereoselective Synthesis of Novel Aza-diketopiperazines via a Domino Cyclohydrocarbonylation/Addition Process. Chem. Commun., 2014, 50, 9657-9660; (e) Dong, K.; Fang, X.; Jackstell, R.; Beller, M. A Novel Rhodiumcatalyzed Domino-hydroformylation-reaction for the Synthesis of Sulphonamides. Chem. Commun., 2015, 51, 5059-5062; (f) Tsai, J.-C.; Lin, Y.-H.; Chen, G.-T.; Gao, Y.-K.; Tseng, Y.-C.; Kao, C.-L.; Chiou, W.-H. Rhodium-Catalyzed Domino Hydroformylation/Double-Cyclization Reaction of Arylacetylenecarboxamides: Diastereoselectivity Studies and Application in the Synthesis of 1-Azabicyclo[x.y.o]alkanes. Chem. Asian J., 2018, 13, 3190-3197.

(5) Green-field, H.; Wotiz, J. H.; Wender, I. Reactions of Acetylenic Compounds under Hydroformylation Conditions. J. Org. Chem. 1957, $22,542-546$

(6) (a) Escher, I.; Glorius F. in Science of Synthesis, Vol. 25 (Ed.: R. Bruckner), Georg Thieme, Stuttgart, 2007, p. 733; (b) Castillon, S.; Fernandez, E. in Rhodium Catalysed Hydroformylation (Ed.: P. W. N. M. van Leuwen and C. Claver), Kluwer, Dordrecht, 2000, p. 178.

(7) Johnson, J. R.; Cuny, G. D.; Buchwald, S. L. Rhodium-Catalyzed Hydroformylation of Internal Alkynes to $\alpha, \beta$-Unsaturated Aldehydes. Angew. Chem. Int. Ed. 1995, 34, 1760-1761.

(8) (a) Van den Hoven, B. G.; Alper, H. Regioselective Hydroformylation of Enynes Catalyzed by a Zwitterionic Rhodium Complex and Triphenyl Phosphite. J. Org. Chem. 1999, 64, 3964-3968; (b) Van den Hoven, B. G.; Alper, H. The First Regioselective Hydroformylation of Acetylenic Thiophenes Catalyzed by a Zwitterionic Rhodium Complex and Triphenyl Phosphite. J. Org. Chem. 1999, 64, 9640-9645.

(9) Ishii, Y.; Miyashita, K.; Kamita, K.; Hidai, M. Selective Hydroformylation of Internal Acetylenes by $\mathrm{PdCl}_{2}\left(\mathrm{PCy}_{3}\right)_{2}$ : Remarkable Synergistic Effect of Cobalt. J. Am. Chem. Soc. 1997, 119, 6448-6449.

(10) Goettmann, F.; Le Floch, P.; Sanchez, C. Highly regioselective terminal alkynes hydroformylation and Pauson-Khand reaction catalysed by mesoporous organised zirconium oxide based powders. Chem. Commun. 2006, 180-182.

(11) Agabekov, V.; Seiche, W.; Breit, B. Rhodium-catalyzed hydroformylation of alkynes employing a self-assembling ligand system. Chem. Sci. 2013, 4, 2418-2422.

(12) (a) Fang, X.; Zhang, M.; Jackstell, R.; Beller, M. Selective Palladium-Catalyzed Hydroformylation of Alkynes to $\alpha, \beta$-Unsaturated Aldehydes. Angew. Chem. Int. Ed. 2013, 52, 4645-4649; (b) Fang, X.; Jackstell, R.; Beller, M. Sequential Hydroformylation/Diels-Alder Processes: One-Pot Synthesis of Polysubstituted Cyclohexenes, Cyclohexadienes, and Phthalates from Alkynes. Chem. Eur. J. 2014, 20, 7939-7942.

(13) Zhang, Z.; Wang, Q.; Chen, C.; Han, Z.; Dong, X.-Q.; Zhang, $X$. Selective Rhodium-Catalyzed Hydroformylation of Alkynes to $\alpha, \beta$ Unsaturated Aldehydes with a Tetraphosphoramidite Ligand. Org. Lett. 2016, 18, 3290-3293.

(14) Tan, G.; Wu, Y.; Shi, Y.; You, J. Syngas-Free Highly Regioselective Rhodium-Catalyzed Transfer Hydroformylation of Alkynes to $\alpha, \beta$-Unsaturated Aldehydes. Angew. Chem. Int. Ed. 2019, 58, 74407444.

(15) Fang, W.; Breit, B. Tandem Regioselective HydroformylationHydrogenation of Internal Alkynes Using a Supramolecular Catalyst. Angew. Chem. Int. Ed. 2018, 57, 14817-14821.

(16) For reviews on ynamides and their reactivity, see: (a) DeKorver, K. A.; Li, H.; Lohse, A. G.; Hayashi, R.; Lu, Z.; Zhang, Y.; Hsung, R. P. Ynamides: A Modern Functional Group for the New Millennium. Chem. Rev. 2010, 110, 5064-5106; (b) Evano, G.; Coste, A.; Jouvin, K. Ynamides: Versatile Tools in Organic Synthesis. Angew. Chem., Int Ed. 2010, 49, 2840-2859; (c) Evano, G.; Jouvin, K.; Coste, A. General Amination Reactions for the Synthesis of Ynamides. Synthesis 2013 , 45, 17-26; (d) Wang, X.-N.; Yeom, H.-S.; Fang, L.-C.; He, S.; Ma, Z.X.; Kedrowski, B. L.; Hsung, R. P. Ynamides in Ring Forming Transformations. Acc. Chem. Res. 2014, 47, 560-5078; (e) Evano, G.; Blanchard, N.; Compain, G.; Coste, A.; Demmer, C. S.; Gati, W.; Guissart, C.; Heimburger, J.; Henry, N.; Jouvin, K.; Karthikeyan, G.; Laouiti, A.; Lecomte, M.; Mingot, A. M.; Metayer, B.; Michelet, B.; Nitelet, A.; Theunissen, C.; Thibaudeau, S.; Wang, J.; Zarca; M.; Zhang, C. A Journey in the Chemistry of Ynamides: From Synthesis to Applications. Chem. Lett. 2016, 574-585; (f) Evano, G.; Michelet, B.; Zhang, C. The anionic chemistry of ynamides: A review. C. R. Chimie 2017, 20, 648-664.

(17) For recent relevant synthetic approaches to aminoacrolein derivatives and their reactivity, see: (a) Stanovnik, B.; Svete, J. Synthesis of Heterocycles from Alkyl 3-(Dimethylamino)propenoates and Related Enaminones. Chem. Rev. 2004, 104, 2433-2480, and references therein; (b) Elassar, A. Z. A.; El-Khair, A. A. Recent developments in the chemistry of enaminones. Tetrahedron 2003, 59, 8463-8480; (c) Belanger, G.; Larouche-Gauthier, R.; Menard, F.; Nantel, M.; Barabe, F. Addition of Tethered Nonaromatic Carbon Nucleophiles to Chemoselectively Activated Amides. Org. Lett. 2005, 7, 4431-4434; (d) Jin, X.; Yamaguchi, K.; Mizuno, N. Gold-Catalyzed Heterogeneous Aerobic Dehydrogenative Amination of $\alpha, \beta$-Unsaturated Aldehydes to Enaminals. Angew. Chem. Int. Ed. 2014, 53, 455-458.

(18) For selected examples of chelation-controlled regioselective metalations of ynamides, see: (a) Gourdet, B.; Lam, H. W. Stereoselective Synthesis of Multisubstituted Enamides via Rhodium-Catalyzed Carbozincation of Ynamides. J. Am. Chem. Soc. 2009, 131, 38023803; (b) Das, J.; Chechik, H.; Marek I. A Unique Approach to Aldol Products for the Creation of All-Carbon Quaternary Stereocentres. Nat. Chem. 2009, 1, 128-132; (c) Minko, Y.; Pasco, M.; Lercher, L.; Botoshansky, M.; Marek, I. Forming All-Carbon Quaternary Stereogenic Centres in Acyclic Systems from Alkynes. Nature 2012, 490, 522-526; (d) Minko, Y.; Pasco, M.; Chechik, H.; Marek, I. Regio- and 
Stereoselective Carbometallation Reactions of $\mathrm{N}$-Alkynylamides and Sulfonamides. Beilstein J. Org. Chem. 2013, 9, 526-532; (e) Takimoto, M.; Gholap, S. S.; Hou, Z. Cu-Catalyzed Alkylative Carboxylation of Ynamides with Dialkylzinc Reagents and Carbon Dioxide. Chem. Eur. J. 2015, 21, 15218-15223; (f) Fopp, C.; Romain, E.; Isaac, K.; Chemla, F.; Ferreira, F.; Jackowski, O.; Oestreich, M.; Perez-Luna, A. Stereodivergent Silylzincation of $\alpha$-Heteroatom-Substituted Alkynes. Org. Lett. 2016, 18, 2054-2057; (g) Doi, R.; Abdullah, I.; Taniguchi, T.; Saito, N.; Sato, Y. Nickel-Catalyzed Hydrocarboxylation of Ynamides with $\mathrm{CO}_{2}$ and $\mathrm{H}_{2} \mathrm{O}$ : Observation of Unexpected Regioselectivity. Chem. Commun. 2017, 53, 7720-7723; (h) Straker, R. N.; Majhail, M. K.; Willis, M. C. Exploiting Rhodium-Catalysed Ynamide Hydroacylation as a Platform for Divergent Heterocycle Synthesis. Chem. Sci. 2017, 8, 7963-7968.

(19) Zhou, B.; Tan, T.-D.; Zhu, X.-Q.; Shang, M.; Ye, L.-W. Reversal of Regioselectivity in Ynamide Chemistry. ACS Catal. 2019, 9, 6393-6406

(20) Kranenburg, M.; van der Burgt, Y. E. M.; Kamer, P. C. J.; van Leeuwen, P. W. N. M.; Goubitz, K.; Fraanje, J. New Diphosphine Ligands Based on Heterocyclic Aromatics Inducing Very High Regioselectivity in Rhodium-Catalyzed Hydroformylation: Effect of the Bite Angle. Organometallics 1995, 14, 3081-3089.
(21) Pongracz, P.; Bartal, B.; Kollar, L.; Mika, L. T. Rhodium-catalyzed hydroformylation $\gamma$-valerolactone as a biomass-derived solvent. Journal of Organometallic Chemistry, 2017, 847, 140-145.

(22) Cuny, G. D.; Buchwald, S. L. Practical, High-Yield, Regioselective, Rhodium-Catalyzed Hydroformylation of Functionalized Alpha-Olefins. J. Am. Chem. Soc. 1993, 115, 2066-2068.

(23) Meyer, T. G.; Fischer, A.; Jones, P. J.; Schmutzler, R. Preparation and Single Crystal X-Ray Diffraction Study of Some Fluorophosphites and Phosphite Esters. Zeitschrift für Naturforschung B, 1993, 48, 659-671.

(24) (a) Tolman, C. A. Electron Donor-Acceptor Properties of Phosphorus Ligands. Substituent Additivity. J. Am. Chem. Soc. 1970, 92, 2953-2956; (b) Tolman, C. A. Steric Effects of Phosphorus Ligands in Organometallic Chemistry and Homogeneous Catalysis. Chem. Rev. 1977, 77, 313-348; (c) Mitoraj, M. P.; Michalak, A. $\sigma$-Donor and $\pi$ Acceptor Properties of Phosphorus Ligands: An Insight from the Natural Orbitals for Chemical Valence. Inorg. Chem. 2010, 49, 578-582; (d) Gonsalvi, L.; Guerriero, A.; Montflier, E.; Hapiot, F.; Peruzzini, M. in Hydroformylation for Organic Synthesis (Eds: M. Taddei, A. Mann), Topics in Current Organic Chemistry vol. 342, Springer-Verlag, Berlin, 2013, pp. 1-47. 